\title{
DEVELOPMENT AND VALIDATION OF A REVERSED-PHASE HPLC METHOD FOR THE SIMULTANEOUS ESTIMATION OF DICYCLOMINE HYDROCHLORIDE AND FAMOTIDINE IN BULK AND TABLETS
}

\author{
SHAILESH T. DONDA, VISHAL B. BAVISKAR, PRASHANT K. DESHMUKH, \\ SANJAY B. BARI, PRAVIN O. PATIL* \\ Department of Quality Assurance, H. R. Patel Institute of Pharmaceutical Education and Research, \\ Karwand Naka, Shirpur. Dist. Dhule 425405 (M.S.)
}

\begin{abstract}
In the present study an isocratic reverse phase-high performance liquid chromatography (RP-HPLC) method was developed and validated for simultaneous estimation of dicyclomine hydrochloride (DCY) and famotidine (FAM) in bulk and pharmaceutical dosage forms. The separation was achieved on a Phenomex Gemini $\mathrm{C}_{18}$ column ( $4.6 \times 250 \mathrm{~mm}, 5 \mu$ particle size) using a mixture of methanol and $0.1 \%$ triethylamine (TEA) pH 3.0 (adjusted with orthophosphoric acid) in the ratio of 40:60 (v/v) as a mobile phase. The flow rate was $1.0 \mathrm{~mL} \mathrm{~min}{ }^{-1}$, column temperature was kept at $28{ }^{\circ} \mathrm{C}$ and detection was monitored at $270 \mathrm{~nm}$. The retention time of dicyclomine hydrochloride and famotidine was found to be 10.72 and 2.72 min respectively. Recovery studies were satisfactory and the correlation coefficient for FAM and DCY were 0.9947 and 0.9935 respectively, indicates linearity of the methods within the limits. The developed method can be used for routine quality control simultaneous analysis of DCY and FAM in tablet dosage form without any interference of excipients.
\end{abstract}

Keywords: Dicyclomine hydrochloride, Famotidine, RP-HPLC

\section{INTRODUCTION}

Dicyclomine (Also called dicycloverine, DCY) hydrochloride (Figure 1) is chemically, 2-(diethyamino) ethyl 1-cyclohexylcyclohexane-1-carboxylate, is a muscarinic antagonist and used as an antispasmodic as well as in urinary incontinence. In addition it does have some local anesthetic properties and is used in gastrointestinal, biliary, and urinary tract spasm ${ }^{1,2}$. Famotidine (FAM) is chemically $3-[(\{2-[($ diaminomethylidene $)$ amino $]-1,3$-thiazol-4-yl $\}$ methyl $)$ sulfanyl] -N'-sulfamoylpropanimidamide (Figure 2). The FAM is a competitive $\mathrm{H}_{2}$-receptor antagonist. This competitive inhibition results in reduced basal and nocturnal gastric acid secretion and a reduction in gastric volume, acidity, and amount of gastric acid released in response to stimuli including food, caffeine, insulin, betazole, or pentagastrin ${ }^{3,4}$. Combination of Dicyclomine and Famotidine is used widely for various clinical complications like Gl spasm, irritable bowel syndrome, hyper-peristalsis, peptic ulcer, flatulence, diarrhoea, benign duodenal and gastric ulcer, reflux oesophagitis, acid peptic disease etc.

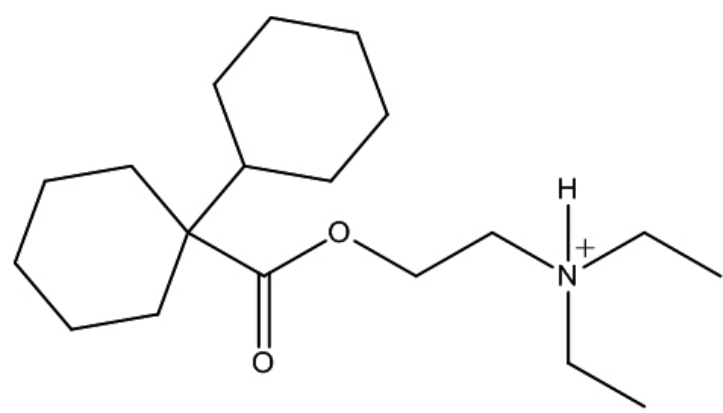

Fig. 1: Chemical structure of Dicyclomine hydrochloride.

Several analytical methods have been reported for quantification of DCY and FAM in biological specimen as well as in formulations. Most of them were used for the determination of FAM alone ${ }^{5}$, in binary combination with, Mefenamic acid-DCY ${ }^{6}$, nimesulide-DCY ${ }^{7}$, moxifloxacin-FAM ${ }^{8}$, diclofenac sodium-FAM ${ }^{9}$, FAM-ibuprofen ${ }^{10}$, tertiary combination lock, DCY-Mefenamic acid-paracetamol ${ }^{2}$, FAM-potential degradates-preservatives ${ }^{11}$ by means of HPLC. Few spectrophotometric methods were mentioned for the estimation of DCY and FAM, FAM alone ${ }^{12}$ and combinations with other drugs viz. DCYmefenamic acid ${ }^{13}$, FAM-domperidone ${ }^{14}$, FAM-ibuprofen ${ }^{15}$, FAM- diclofenac potassium ${ }^{16}$. Estimation of DCY and FAM alone was also mentioned in United State Pharmacopoeia using HPLC ${ }^{17}$.

A combination of DCY and FAM is commercially available in solid
(Tablet) dosage form. The literature reveals that no analytical methods were existing for simultaneous determination of these two drugs in combination. Therefore, the main objective of the present investigation was to develop simple, fast, accurate and sensitive method which could be applied to simultaneous analyses of DCY and FAM in bulk and tablets.

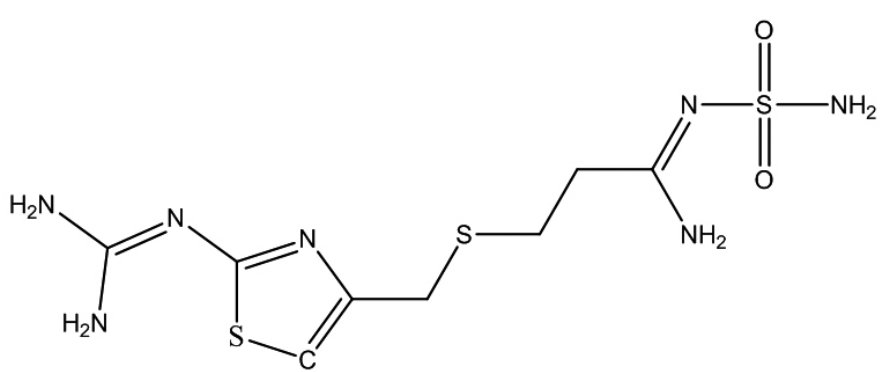

Fig. 2: Chemical structure of Famotidine.

\section{EXPERIMENTAL}

Material and Reagents

A gift sample of dicyclomine was obtained from Alaric Healthcare Pvt. Ltd. (India) and FAM from Lincoln Pharmaceutical Ltd. (India). HPLC grade methanol purchased from Merck, Darmstadt, Germany and was used throughout experimentation. Double distilled water was used to prepare all solutions and filtered through a $0.45 \mu \mathrm{m}$ filter. Analytical grade orthophosphoric acid (OPA) was purchased from S. D. Fine Chemicals, Mumbai. Pharmaceutical dosage form containing DCY and FAM was purchased from local markets. Each tablet was labelled to contain DCY $10 \mathrm{mg}$ and FAM $20 \mathrm{mg}$.

Instrumentation

Analysis was performed on a Shimadzu HPLC system with inbuilt PDA detector was utilized for method development and validation. The chromatography software LC solution was used for data collection and processing. The analytical column was Phenomex Gemini $\mathrm{C}_{18}$ column $(4.6 \mathrm{x}$ $250 \mathrm{~mm}, 5 \mu$ particle size).

Chromatographic Conditions

Simultaneous separation of DCY and FAM was performed using an isocratic mobile phase consisted of a mixture of methanol and $0.1 \%$ triethylamine (TEA) pH 3.0 (adjusted with OPA) in the ratio of 40:60 (v/v). The well resolved, sharp peak for FAM and DCY was obtained at a retention time of $2.37 \mathrm{~min}$ and $10.72 \mathrm{~min}$ respectively. The flow rate was maintained at $1.0 \mathrm{~mL} \mathrm{m^{-1 }}$, UV detection was performed at $270 \mathrm{~nm}$. 
Preparation of standard stock and sample solution

An accurate weighted FAM $(10 \mathrm{mg})$ reference standard was transferred to a $10 \mathrm{ml}$ volumetric flask and was dissolved in the mobile phase to make a solution of $1000 \mu \mathrm{g} \mathrm{mL}^{-1}$. From this stock solution, by the serial dilution, required concentration of $20,40,60,80,100,120 \mu \mathrm{g} \mathrm{mL}^{-1}$ were prepared.

An accurate weighted DCY $(10 \mathrm{mg})$ reference standard was transferred to a $10 \mathrm{ml}$ volumetric flask and was dissolved in the mobile phase to make a solution of $1000 \mu \mathrm{g} \mathrm{mL}^{-1}$. From this stock solution, by the serial dilution, required concentration of $10,20,30,40,50,60 \mu \mathrm{g} \mathrm{mL}^{-1}$ were prepared.

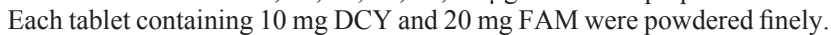
A composite of 20 tablets was prepared by grinding them to a fine, uniform size powder. A quantity of powder which equivalent to $10 \mathrm{mg}$ DCY, and 20 mg FAM were transfered in $10 \mathrm{~mL}$ volumetric flask and dilute up to $10 \mathrm{~mL}$ of mobile phase and sonicate for 15 minute then filtered through $0.45 \mu \mathrm{m}$ filter paper. From this solution $0.2 \mathrm{ml}$ was transferred in $10 \mathrm{ml}$ volumetric flask and diluted up to the mark with mobile phase to obtain a sample solution containing $20 \mu \mathrm{g} \mathrm{mL}^{-1}$ of DCY and $40 \mu \mathrm{g} \mathrm{mL}^{-1}$ of FAM.

Method validation

The proposed method was validated as per International Conference Harmonization guidelines for various parameters like accuracy, precision, linearity, robustness, system suitability ${ }^{18}$. The replicate of the drug were carried out to assess the system suitability. It was further evaluated by analyzing the peaks, tailing factor, repeatability, theoretical plates of the column, resolution between the peaks, peak symmetry and relative retention time.

\section{RESULT AND DISCUSSION}

\section{Method development and Optimization}

A RP-HPLC method was optimized with an intention to develop an accurate and reproducible method for simultaneous estimation of DCY and FAM. Isocratic elution is simple, requires only one pump and flat baseline separation for easy and reproducible results. Both drugs showed absorbance at $270 \mathrm{~nm}$. Therefore the wavelength selected for the determination of DCY and FAM was $270 \mathrm{~nm}$. The final chromatographic conditions were set for stationary phase giving satisfactory resolved peak and run time with reversed phase Phenomex Gemini $C_{18}$ column $(4.6$ x $250 \mathrm{~mm}, 5 \mu$ particle size) column. A series of mobile phases consisted of varying $\mathrm{pH}$ and volume fractions of methanol and water were tested and the best results were obtained using the mobile phase consisted of methanol: $0.1 \%$ triethylamine, $\mathrm{pH} 3$ (adjusted with OPA), in 40:60 giving well resolved, sharp peak for FAM and DCY with a retention time (tR) of $2.37 \mathrm{~min}$ and $10.72 \mathrm{~min}$ respectively (Fig. 3). The flow rate of $1.0 \mathrm{~mL} \mathrm{~min}^{-1}$ at $270 \mathrm{~nm}$ and ambient temperature for column oven $\left(28^{0}\right.$ C) was found to be the best for analysis.

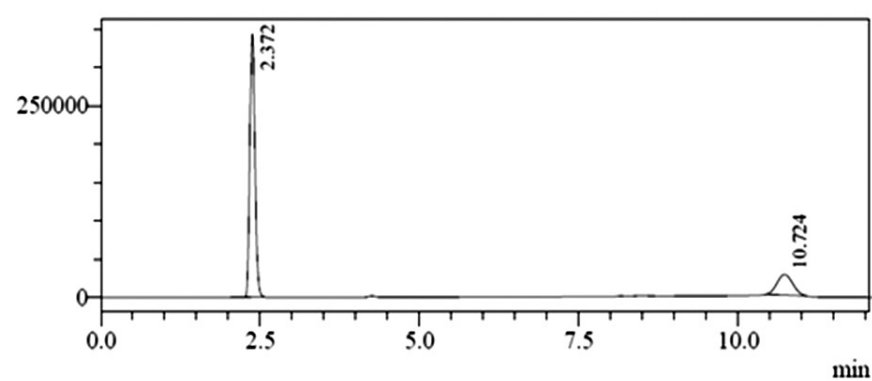

Figure 3 A typical chromatogram of a mixture of FAM and DCY.

This isocratic-mode method with PDA detection was developed for the determination of the active ingredients, DCY and FAM. Initially, the reversedphase column was checked and tested. The system suitability carried out as per specified ICH guidelines ${ }^{18}$.

In trial 1, the mobile phase consisted of methanol and water in a ratio of (70:30 v/v, pH 3.0 adjusted with OPA) with a flow rate $1.0 \mathrm{ml} \mathrm{min}^{-1}$ was tried and chromatogram obtained from combination DCY and FAM had showed a broad peak of DCY with lesser number of theoretical plates. While in trial 2, the mobile phase consisted of acetonitrile and $0.1 \%$ triethylamine in the ratios of $\left(60: 40 \mathrm{v} / \mathrm{v}, \mathrm{pH} 3.0\right.$ adjusted with OPA) with a flow rate $1.0 \mathrm{~mL} \mathrm{~min}^{-1}$ was attempted. A chromatogram revealed much lesser retention time for FAM. On the other hand in trial 3, the mobile phase consisted of methanol and $0.1 \%$ triethylamine in the ratios of $(60: 40 \mathrm{v} / \mathrm{v}, \mathrm{pH} 3.0$ adjusted with OPA) with a flow rate $1.0 \mathrm{ml} \mathrm{min} \mathrm{m}^{-1}$ was utilized and chromatogram obtained again showed the less retention time for FAM and theoretical plate was within the limit. In trial 4 , the mobile phase consisted of methanol and $0.1 \%$ triethylamine in the ratios of $\left(40: 60 \mathrm{v} / \mathrm{v}, \mathrm{pH} 3.0\right.$ adjusted with OPA) with a flow rate $1.0 \mathrm{~mL} \mathrm{~min}^{-1}$ was utilized and chromatogram obtained showed the retention time for FAM $2.37 \mathrm{~min}$, DCY $10.72 \mathrm{~min}$ and all other criteria's were found to be within the limit. Chromatogram for FAM and DCY were shown in Figure 3. The system suitability parameter is an important part of chromatographic method and is used to verify that the resolution and reproducibility of the system were adequate for the analysis to be performed (Table 1).

Table 1 System suitability parameters for DCY and FAM.

\begin{tabular}{|c|c|c|c|c|}
\hline Parameters & $\begin{array}{c}\text { Retention } \\
\text { Time (tR) }\end{array}$ & $\begin{array}{c}\text { Theoretical } \\
\text { plates (N) }\end{array}$ & $\begin{array}{c}\text { Resolution } \\
\text { (Rs) }\end{array}$ & $\begin{array}{c}\text { Tailing } \\
\text { Factor (T) }\end{array}$ \\
\hline FAM & 2.37 & 3406.71 & \multirow{2}{*}{26.52} & 1.18 \\
\cline { 1 - 3 } DCY & 10.72 & 8433.90 & & 1.09 \\
\hline
\end{tabular}

\section{Method validation}

Linearity

Standard curves of DCY and FAM were linear $\left(\mathrm{r}^{2}=0.9935\right.$ and $\mathrm{r}^{2}=0.9947$ respectively) over the concentration range of $10-60 \mu \mathrm{g} \mathrm{mL}^{-1}$ and $20-120 \mu \mathrm{g}$ $\mathrm{mL}^{-1}$ respectively. The linearity equation was $\mathrm{y}=11705 \mathrm{x}+377435$ for DCY and $y=25074 x+1675106$ for FAM where ' $y$ ' is the peak area and ' $x$ ' is concentration in $\mu \mathrm{g} \mathrm{mL}^{-1}$.

Accuracy

Accuracy was determined by evaluating the percentage of recovery of known analytes to the pharmaceutical formulation. Each sample was injected three times and accuracy was determined at $80 \%, 100$ and $120 \%$. The accuracy was expressed as the percentage of the analyte recovered. The result of accuracy studies were shown in Table 2.

Table 2 Results of Accuracy study.

\begin{tabular}{|c|c|c|c|c|c|}
\hline \multirow{2}{*}{ Drugs } & $\begin{array}{c}\text { Amount } \\
\text { Added } \\
\mathbf{( \% )}\end{array}$ & $\begin{array}{c}\text { Amount } \\
\text { Recovery } \\
\mathbf{( \% )}\end{array}$ & $\begin{array}{c}\text { Mean } \\
\text { Recovery } \\
\mathbf{( \% )}(\mathbf{n}=\mathbf{3})\end{array}$ & S.D & R.S.D \\
\hline \multirow{3}{*}{ FAM } & 80 & 100.90 & & 0.47 & 0.65 \\
\cline { 2 - 3 } & 100 & 99.07 & \multirow{2}{*}{99.55} & 0.95 & 1.20 \\
\cline { 2 - 3 } \cline { 5 - 6 } & 120 & 98.69 & & 1.21 & 1.40 \\
\hline \multirow{3}{*}{ DCY } & 80 & 100.34 & & 0.32 & 0.89 \\
\cline { 2 - 3 } & 100 & 100.75 & \multirow{2}{*}{100.46} & 0.39 & 0.98 \\
\cline { 2 - 3 } \cline { 5 - 6 } & 120 & 100.31 & & 0.72 & 1.64 \\
\hline
\end{tabular}

Precision

The precision of this method was determined by inter-day, intra-day and repeatability precision. It was expressed as \% R.S.D. of a series of measurement. The experimental values obtained for the intra-day and inter-day precision of DCY and FAM in sample were shown in Table 3. The results obtained for the repeatability of DCY and FAM in sample was shown R.S.D. less than 2, indicating good repeatability. The \% RSD was less than 2 in intraday, interday precision and all parameters of robustness were within the limit. Thus the proposed method is precise and accurate. All the value and data obtained were within the acceptance criteria.

Limit of detection (LOD) and Limit of quantification (LOQ)

The LOD and LOQ were calculated by using the equations LOD $=(3.3 \times$ $\sigma) / \mathrm{S}$ and $\mathrm{LOQ}=(10 \times \sigma) / \mathrm{S}$ respectively, where ' $\sigma$ ' is the standard deviation of the peak areas of the drug $(n=3)$ and ' $\mathrm{S}$ ' is the slope of the corresponding calibration plot. The LOD were $2.43 \mu \mathrm{g} \mathrm{mL}^{-1}$ and $4.33 \mu \mathrm{g} \mathrm{mL}^{-1}$ and LOQ were $7.38 \mu \mathrm{g} \mathrm{mL}^{-1}$ and $13.13 \mu \mathrm{g} \mathrm{mL}^{-1}$ for DCY and FAM respectively.

Robustness

To evaluate robustness, various parameters like mobile phase, flow rate, detection wavelength were deliberately varied for estimation of DCY and FAM (Table 4). 
Table 3 Results of Precision study.

\begin{tabular}{|c|c|c|c|c|c|}
\hline & Drug & $\begin{array}{l}\text { Amount Taken } \\
\left(\mu \mathrm{g} \mathrm{mL}^{-1}\right)\end{array}$ & $\begin{array}{l}\text { Mean Amount Found } \\
\left(\mu \mathrm{g} \mathrm{mL}^{-1}\right)(\mathrm{n}=3)\end{array}$ & S.D & \%R.S.D \\
\hline \multirow{6}{*}{ Intraday } & \multirow{3}{*}{ FAM } & 40 & 39.95 & 0.73 & 1.833 \\
\hline & & 60 & 60.37 & 1.25 & 0.866 \\
\hline & & 80 & 79.67 & 1.66 & 1.326 \\
\hline & \multirow{3}{*}{ DCY } & 20 & 19.35 & 0.97 & 0.902 \\
\hline & & 30 & 31.96 & 0.61 & 0.451 \\
\hline & & 40 & 39.85 & 2.35 & 1.863 \\
\hline \multirow{6}{*}{ Interday } & \multirow{3}{*}{ FAM } & 40 & 39.78 & 1.04 & 0.783 \\
\hline & & 60 & 61.16 & 1.40 & 0.719 \\
\hline & & 80 & 79.70 & 1.30 & 1.193 \\
\hline & \multirow{3}{*}{ DCY } & 20 & 20.38 & 1.05 & 0.977 \\
\hline & & 30 & 30.25 & 1.19 & 1.153 \\
\hline & & 40 & 40.39 & 1.08 & 0.748 \\
\hline
\end{tabular}

Table 4 Results of Robustness study.

\begin{tabular}{|c|c|c|c|c|c|c|c|c|}
\hline Parameter & Variation & \multicolumn{3}{|c|}{ FAM } & \multicolumn{3}{|c|}{ DCY } & $\begin{array}{c}\text { FAM/DCY } \\
\text { Resolution } \\
\text { (Rs) }\end{array}$ \\
\hline \multirow[t]{2}{*}{ Flow rate } & $1.0 \mathrm{~mL}$ & 2.37 & 3406 & 1.18 & 10.72 & 8433 & 1.09 & 26.52 \\
\hline & $1.1 \mathrm{~mL}$ & 2.31 & 3267 & 1.17 & 9.97 & 7796 & 1.06 & 23.49 \\
\hline \multirow[t]{2}{*}{ Mobile phase } & $40: 60$ & 2.37 & 3406 & 1.18 & 10.72 & 8433 & 1.09 & 26.52 \\
\hline & $42: 58$ & 2.33 & 3479 & 1.16 & 9.75 & 8351 & 1.03 & 25.52 \\
\hline \multirow[b]{2}{*}{ Wavelength } & 268 & 2.33 & 3318 & 1.19 & 9.07 & 8341 & 1.12 & 24.76 \\
\hline & 270 & 2.37 & 3406 & 1.18 & 10.72 & 8433 & 1.09 & 26.52 \\
\hline
\end{tabular}

Assay

The proposed method was evaluated in the assay of commercially available tablet containing DCY (10mg) and FAM (20mg) six replicate determination

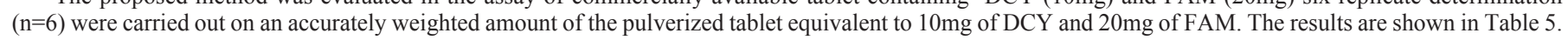

Table 5 Assay of tablet formulation containing FAM and DCY.

\begin{tabular}{|c|c|c|c|}
\hline Component & Labeled Amount (mg) & $\begin{array}{c}\text { Mean Amount Found } \\
\text { (mg) (n=6) }\end{array}$ & $\begin{array}{c}\text { \%Amount Found } \\
\text { Mean (n=6) }\end{array}$ \\
\hline FAM & 20 & 20.08 & 100.41 \\
\hline DCY & 10 & 9.95 & 1.56 \\
\hline
\end{tabular}

Specificity and selectivity

The specificity of the RP-HPLC method was determined by comparison of the chromatogram of mixed standards and sample solutions. The specificity test of the proposed method demonstrated that the excipients from tablets do not interfere in the drug peak around the retention time of DCY and FAM and also baseline showed no any significant noise. The studying the effect of excipients on quantification of DCY and FAM, a placebo was analyzed. The results obtained indicate that excipients had no interference with proposed quantification of DCY and FAM. The results obtained indicate that excipients had no interference with proposed quantification of DCY and FAM. The method is quite selective.

\section{CONCLUSION}

A new RP-HPLC method has been developed for the simultaneous estimation of DCY and FAM in bulk and pharmaceutical formulations. The method gave good resolution for both drugs with a short analysis time less than 12 minutes. The good percentage recoveries in the tablet dosage form suggest that the excipients present in the dosage form had no interference in the determination of active constituents. The proposed method can be used for routine analysis of DCY and FAM in tablet dosage form. The method was validated as per ICH guidelines.

\section{Declaration of Interest:}

The authors report no declarations of interest.

\section{ACKNOWLEDGEMENTS}

The authors are thankful to H.R. Patel Institute of Pharmaceutical Education and Research, Shirpur (M.S.), India for providing facilities to carry out this 
research work and also thankful to the Alaric Healthcare Pvt. Ltd. (India) for providing a gift sample of dicyclomine as well as Lincoln Pharmaceutical Pvt. Ltd. (India) for providing an authentic sample of famotidine.

\section{REFERENCES}

1. British Pharmacopoeia; Department of Health and Stationary office under the controller of majesty officer for Health minister UK, Vol. 1, 2005; pp 649.

2. S. R. Lokhande, S. M. Mhetre, S. S. Pekamwar, T. M. Kalyankar, World Journal of Pharmacy and Pharmaceutical Sciences. 1, 968 (2012).

3. Indian Pharmacopoeia, Ministry of Health and Family Welfare, Government of India, The Indian Pharmacopeial Commission, Ghaziabad, 2007; pp. 1022.

4. http://www.drugbank.ca/drugs/DB00927 (Accessed on 21/07/2012).

5. G. Carlucci, P. Mazzeo, C. Vetuschi, E. D. Giuseppe, International Journal of Pharmaceutics. 102, 211 (1994).

6. D. Prajapati, H. Raj, Int. J. Bio. Sci. 3, 611 (2012).

7. L. Singh, S. Nanda, Research Journal of Pharmacy and Technology. 3, $562(2010)$.

8. N. Sultana, M. Akhtar, S. Shamim, S. Gul, Quim. Nova. 34, 683 (2011).
9. M. V. Modi, M. M. Patel, C. N. Patel, P. D. Bharadia, Inventi Impact: Pharma Ana. \& Qual. Assur. 74 (2011).

10. N. Nyola, J. S. Govinda, Journal of Applied Pharmaceutical Science. 2, 79 (2012).

11. S. E. Biffar, D. J. Mazzo, Journal of Chromatography. 363, 243 (1986).

12. O. Z. Devi, K. Basavaiah, P. J. Ramesh, K. B. Vinay, Farmacia. 59, 647 (2011).

13. M. Moradiya, K. Vadalia, Z. R. Dedania, Inventi Rapid: Pharm. Ana. \& Qual. Assur. 425 (2012)

14. R. Sahu, P. Nagar, S. Bhattacharya, D. Jain, Indian J. Pharm. Sci, 68, 503 (2006).

15. N. Nyola, J. S. Govinda, M. Kumawat, N. Kalra, G. Singh, International Research Journal of Pharmacy. 3, 277 (2012).

16. A. R. Umarkar, S. A. Mehta, D. R. Chaple, L. T. Thote, Journal of Pharmacy Research. 4, 978 (2011).

17. The United State Pharmacopeia $32^{\text {nd }}$ edition $/$ The National Formulary $27^{\text {th }}$ edition, The Official Compendia of Standards, 2009; pp. 2130, 2345.

18. Harmonized Tripartite Guideline, Q2 (R1): Validation of Analytical Procedures: Text and Methodology, (2005). 